\title{
A new scoring system to predict the incidence of new onset diabetes after transplantation (NODAT)
}

\section{ABSTRACT}

Background. We performed this study to develop a new scoring system to stratify different levels of risk of developing new onset diabetes after transplantation (NODAT) in patients who underwent renal transplantation. Many prognostic variables have been previously described but few efforts have been made to group them in order to enhance their individual predictive power.

Material and methods. In a first phase, 100 patients were prospectively analysed to determine which factors were significantly associated with the development of NODAT. A risk score ranging from 0 to 10 points was developed using a multivariate analysis. In a second phase, such score was validated in a new sample of 100 patients.

Results. BMI $\geq 23.5 \mathrm{~kg} / \mathrm{m}^{2}$, age $\geq 38.5$ years, fasting blood sugar at $1^{\text {st }}$ post-operative day $\geq 159.5 \mathrm{mg} / \mathrm{dL}$, fasting blood sugar at $5^{\text {th }}$ post-operative day $\geq 122.5$ $\mathrm{mg} / \mathrm{dL}$ and HOMA-IR $\geq \mathbf{2 . 5}$ were found as independent prognostic variables. A clear distinction was shown among categories of low, intermediate and high risk, defined according to the risk score.

Conclusion. This new scoring framework is basic and simple to accomplish. It permits a generally excellent stratification of risk of developing NODAT in patients

Address for correspondence:

Dr Debmalya Sanyal

Department of Endocrinology

KPC Medical College, Jadavpur, Kolkata

West Bengal, India

e-mail: drdebmalyasanyal@gmail.com

Clinical Diabetology 2020, 9, 4, 226-232

DOI: $10.5603 /$ DK.2020.0024

Received: 01.03.2020

Accepted: 04.05.2020 undergoing renal transplantation. They might be separated in three risk stratification cohorts, which could be of help in early identification of NODAT. (Clin Diabetol 2020; 9; 4: 226-232)

Key words: NODAT, risk score, India, renal transplantation

\section{Introduction}

New-onset diabetes after transplantation (NODAT) refers to diabetes that occurs in previously non-diabetic persons after solid-organ transplantation, according to International consensus guidelines published in 2003 $[1,2]$. There are many risk factors of NODAT. Some risk factors are the same as in general risk factors for diabetes mellitus (DM), while some others are specific to transplantation.

Some common risk factors include age, obesity, African-American and Hispanic [3-6]. In addition, some risk factors are unique to the transplant population. These include specific agents used for immunosuppression, human leukocyte antigen mismatch, donor sex and type of underlying renal disease [7]. Impaired glucose tolerance prior to transplant [8] and hyperglycaemia in the immediate perioperative period $[9,10]$ may identify patients at higher risk for the development of NODAT. There is paucity of data with regards to the development of risk scores for the development of new onset diabetes after transplantation (NODAT) from South-East Asian population. Although data from western population are available, we intended to develop the same for our population which is place of residence for almost one-fifth of the world's population. Furthermore, the pre-transplant and peri-transplant 
risk factors in our study population also differ considerably from the western population which calls for development of population specific predictive model for development of NODAT in the intended population. We conducted the present study to test the prognostic value of a combination of such risk factors resulting in a prospectively designed score that could be capable of making a clear distinction of different clinical outcomes with regards to development of NODAT applied to patients coming to hospital for renal transplantation. With that purpose we chose the most widely available prognostic variables that, in our model, provided the best independent information for the development of NODAT. The new score was applied in another cohort of patients consecutively admitted to renal transplant units who were not enrolled in trials of therapeutic interventions.

\section{Material and methods}

\section{Study population}

This was a single-centred prospective study of 200 subjects who underwent renal transplantation over a period of four years in a tertiary care centre in eastern India.

The inclusion criteria comprised of adult subjects with end stage renal disease who underwent live donor kidney transplantation and absence of diabetes prior to kidney transplantation, defined according to the American Diabetes Association (ADA) guideline. None of these patients were on any oral hypoglycaemic agents or insulin prior to kidney transplantation. All patients received their allograft from a living (related or unrelated) donor. All subjects received standard immunosuppressive medications that included triple immunosuppressive medications namely tacrolimus, mycophenolate mofetil or mycophenolate sodium and steroids with induction (ATG). Immunosuppressive therapy comprised tacrolimus (initiation dose of $0.15 \mathrm{mg} / \mathrm{kg}$ ) (with target blood level of tacrolimus 10-15 $\mathrm{ng} / \mathrm{ml}$ between $1^{\text {st }} 3$ month, 5-10 $\mathrm{ng} / \mathrm{ml}$ between $3^{\text {rd }}$ to $6^{\text {th }}$ month and $3-5 \mathrm{ng} / \mathrm{ml}$ in $6^{\text {th }}$ to $12^{\text {th }}$ month), prednisolone $(20 \mathrm{mg} / \mathrm{d}$ ) (with gradual tapering of dose $2.5 \mathrm{mg}$ per month with target of $5 \mathrm{mg}$ at the end of $6^{\text {th }}$ month), and or mycophenolate mofetil $(1.5 \mathrm{~g} / \mathrm{d})$. Previous studies in NODAT have modified the immunosuppressive regimen to prevent NODAT development. But ADA recommends that immunosuppressive regimens associated with best patient and graft survival should be used, irrespective of post-transplantation diabetes mellitus risk [11]. Subjects who were capable of understanding the study and gave informed written consent for study participation were only included. Patients with a diagnosis of DM prior to kidney trans- plantation based on ADA criteria, for diagnosis of DM [12], or those receiving anti-diabetic medications or those who were not capable of providing consent were excluded from the study.

'Prediabetes' in our study was defined according to ADA 2016 guidelines as $\mathrm{HbA}_{1 \mathrm{c}}$ value 5.7-6.4\%. Those who are non-diabetic and underwent renal transplantation are further evaluated for the development of NODAT during 1-year post-transplantation follow-up. Post-transplant follow-up done on weekly basis for $1^{\text {st }}$ month, every $15^{\text {th }}$ day from $1^{\text {st }}$ month to $3^{\text {rd }}$ month, monthly from $3^{\text {rd }}$ month to $12^{\text {th }}$ month. Each transplant patient was followed up for 1-year post-transplant or for 6 months post-development of NODAT, whichever is later. NODAT was defined according to standard ADA criteria provided the patient was receiving therapy (oral hypoglycaemic drugs or insulin) at 3 months posttransplant. Immediate posttransplant hyperglycaemia was defined as a random blood sugar (RBS) $\geq 200 \mathrm{mg} / \mathrm{dL}$ [1] or requirement of insulin on $>2$ days whereas the patient was of dextrose-containing fluid infusions (usually from the $4^{\text {th }}$ postoperative day).

In addition to routine transplant workup, pretransplant BMI, family history of $\mathrm{DM}, \mathrm{HbA}_{1 \mathrm{c}^{\prime}}$ fasting insulin level, fasting C-peptide level, serology for hepatitis B, C and serum magnesium level were evaluated in all patients 2 days prior to transplant. Pre-operative insulin resistance (HOMA-IR), insulin sensitivity (HOMA-S) beta-cell function (HOMA-B and C-peptide levels) were assessed. All the above pre-transplant variables were further compared between NODAT and non-NODAT subjects at the end of the study to assess their strength of association.

\section{Data management and statistical analysis}

Descriptive statistics was analysed with SPSS version 17.0 software for windows. In order to develop a risk score, all demographic, clinical, and biochemical variables were routinely collected. Continuous variables were presented as mean \pm SD and analysed by unpaired $t$ test. Categorical variables were expressed as frequencies and percentages. Nominal categorical data between the groups were compared using Chi-square test or Fischer's exact test as appropriate. A p value of $<0.05$ was considered to be statistically significant. Univariate was analysis done to evaluate odds ratio of various parameters associated with increased risk of NODAT among study population.

Every variable resulting in a $p$ value $<0.01$ in the univariate model was entered into a multiple logistic regression analysis to determine which were independently related to the end-points.

The predictive accuracy of the multivariate model was evaluated using the $C$ statistic, an index that 
Table 1. Baseline characteristics of the subjects who developed NODAT in development phase and validation phase

\begin{tabular}{|c|c|c|}
\hline & Development phase $(n=100)$ & Validation phase $(n=100)$ \\
\hline Age (years), mean (SD) & $45.2(10.93)$ & $46(11)$ \\
\hline Family $\mathrm{H} / \mathrm{O}$ diabetes mellitus, $\mathrm{n}(\%)$ & $25(25)$ & $32(32)$ \\
\hline BMI $\left[\mathrm{kg} / \mathrm{m}^{2}\right]$, mean (SD) & $22.62(4.03)$ & $23.15(5.77)$ \\
\hline Hepatitis B infection, n (\%) & $3(3)$ & $3(3)$ \\
\hline Hepatitis C infection, $\mathrm{n}(\%)$ & $3(3)$ & $3(3)$ \\
\hline Autosomal dominant polycystic kidney disease, $n(\%)$ & $4(4)$ & $3(3)$ \\
\hline Mean magnesium levels [mEq/L], mean (SD) & $1.84(0.51)$ & $1.88(0.37)$ \\
\hline Mean total cholesterol levels [mg/dL], mean (SD) & $139.41(35.01)$ & $136(21)$ \\
\hline Mean triglyceride levels [mg/dL], mean (SD) & $84.02(64.52)$ & $89.5(57.21)$ \\
\hline Pre-operative $\mathrm{HbA}_{1 \mathrm{c}}>5.7 \%, \mathrm{n}(\%)$ & $14(14)$ & $16(16)$ \\
\hline Pre-operative $\mathrm{HbA}_{1 \mathrm{c}}(\%)$, mean (SD) & $5.34(0.16)$ & $5.12(0.1)$ \\
\hline ABO compatibility transplant, $n(\%)$ & $94(94)$ & $96(96)$ \\
\hline HOMA-IR, mean (SD) & $1.87(1.08)$ & $1.84(1.11)$ \\
\hline HOMA-S, mean (SD) & $79.35(48.07)$ & $84.57(40.18)$ \\
\hline HOMA-beta cell function, mean (SD) & $64.14(3.64)$ & $68.23(4.21)$ \\
\hline C-peptide level, mean (SD) & $11.06(5.09)$ & $10.21(6.21)$ \\
\hline
\end{tabular}

Table 2. The results of the univariate analysis

\begin{tabular}{lccc}
\hline Variable & OR & $95 \%$ Cl & P value \\
\hline Age (years), mean \pm SD & 1.084 & $1.033-1.138$ & 0.004 \\
Family H/O diabetes, $\mathrm{n}(\%)$ & 1.133 & $1.013-1.890$ & $<0.001$ \\
Fasting blood sugar-day 1 [mg/dL] & 2.032 & $1.412-3.785$ & $<0.001$ \\
BMI [kg/m²], mean \pm SD & 1.363 & $1.178-1.577$ & $<0.001$ \\
Hepatitis B infection, $\mathrm{n}(\%)$ & 7.4 & $0.638-85.81$ & 0.28 \\
Hepatitis C infection, $\mathrm{n}(\%)$ & 7.4 & $0.638-85.81$ & 0.28 \\
Fasting blood sugar-day 5, mean \pm SD & 9.28 & $5.413-16.519$ & $<0.001$ \\
Autosomal dominant polycystic kidney disease & 1.001 & $0.856-1.087$ & 0.242 \\
Mean magnesium level [mEq/L], mean \pm SD & 0.780 & $0.315-1.930$ & 0.305 \\
Mean total cholesterol level [mg/dL], mean \pm SD & 1.015 & $0.997-1.032$ & 0.120 \\
Mean triglycerides level [mg/dL], mean \pm SD & 1.008 & $0.998-1.018$ & 0.066 \\
Pre-operative HbA ${ }_{1 \mathrm{c}}(\%)>$ 5.7\% & 2.315 & $1.389-2.561$ & $<0.001$ \\
Pre-operative HbA ${ }_{1 \mathrm{c}}(\%)$, mean \pm SD & 1.057 & $1.029-1.185$ & 0.001 \\
ABO compatibility transplant & 0.135 & $0.023-0.792$ & $<0.001$ \\
HOMA-IR & 0.987 & $0.932-0.998$ & 0.001 \\
HOMA-S & 0.957 & $0.921-0.997$ & $<0.001$ \\
HOMA-beta cell function & 0.956 & $0.901-0.978$ & 0.001 \\
C-peptide level & 1.987 & $1.057-2.184$ & $<0.001$ \\
\hline
\end{tabular}

reflects the area under the receiver operating characteristic curve.

The odds ratio (OR) values obtained in the multivariate analysis were used to develop the scoring system in the following way: if the OR was between 1 and 1.9, one point was adjudicated; two points if it was between 2 and 2.9; three points between 3 and 3.9 and four points if it exceeded the last value.
Once the risk score was developed, we conducted a validation phase to assess its prognostic accuracy in a prospectively collected new sample of patients.

The overall predictive ability of the risk score was then assessed with the $C$ statistic and compared with that obtained from the multivariate model of the development phase. 


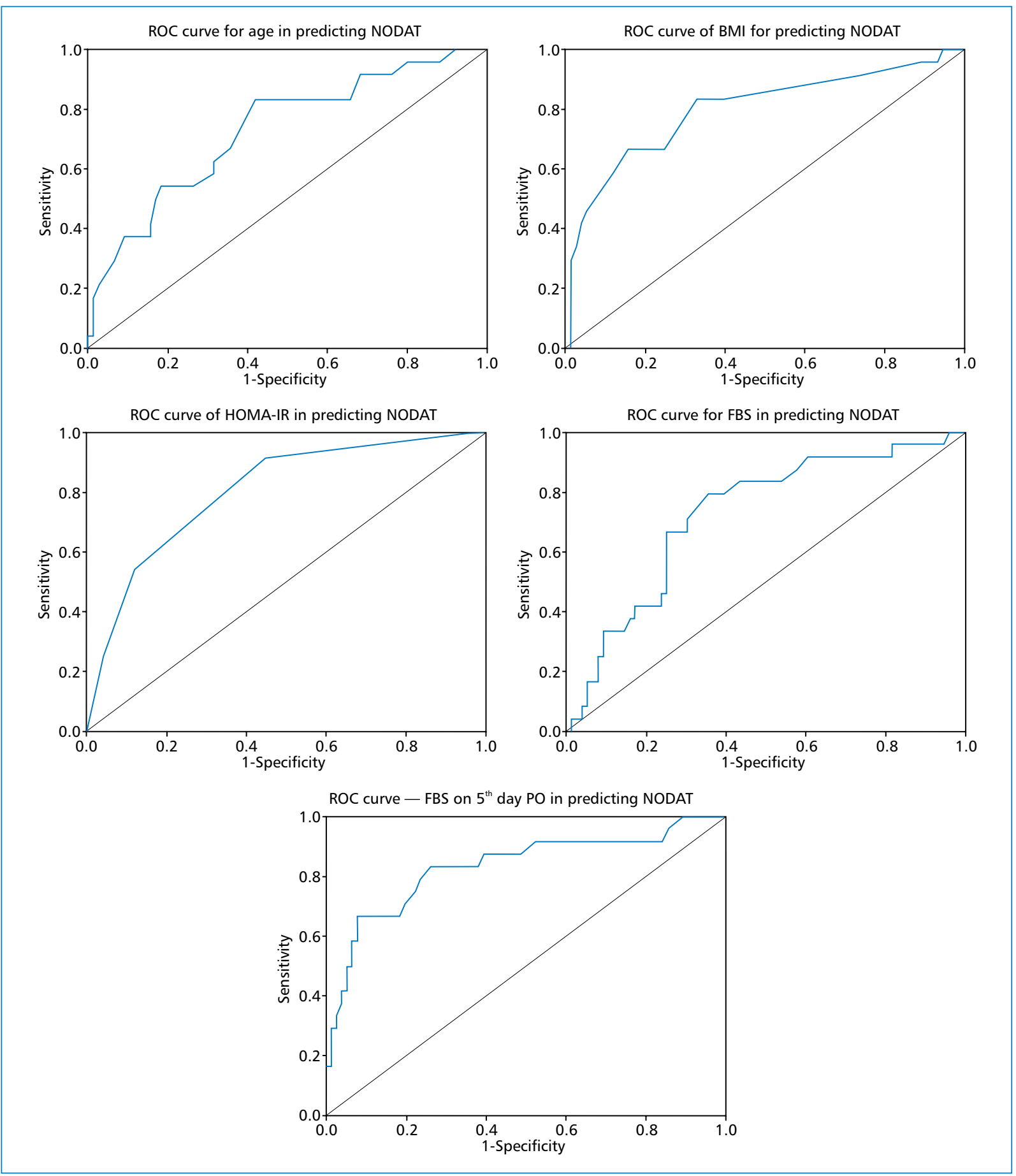

Figure 1. ROC of the significant predictor variables

\section{Results}

\section{Score development phase}

One hundred patients were prospectively included in this phase. Among the 100 subjects included in the analysis, 24 patients (19 males and 5 females) developed NODAT during 1 year of follow-up after transplantation.
Eighteen variables were included in the univariate analysis. We included the variables which had a $p$ value less than 0.010 for multivariate analysis. Hence, we included 14 variables in the multiple regression model and only BMI, age, fasting blood sugar at $1^{\text {st }}$ and $5^{\text {th }}$ post-operative day and HOMA-IR were found as independent prognostic variables of NODAT. The $C$ 
Table 3. Results of the multivariate analysis

\begin{tabular}{lcccccc}
\hline & B - coefficient & C - statistics & Best cut-off & Sensitivity & Specificity & OR, 95\% Cl \\
\hline Age & 0.703 & 0.76 & 38.5 & 83.33 & 71.4 & $1.231(1.133-1.938)$ \\
BMI & 0.821 & 0.80 & 23.5 & 75.6 & 84.2 & $2.103(1.278-2.878)$ \\
HOMA-IR & 1.439 & 0.81 & 2.5 & 74.2 & 78.8 & $4.062(2.79-5.81)$ \\
FBS-1 $^{\text {st }}$ day POD & 0.694 & 0.72 & 159.5 & 77.6 & 82.9 & $1.011(1.002-1.018)$ \\
FBS-5 $^{\text {th }}$ POD & 0.936 & 0.84 & 122.50 & 79 & 92.1 & $2.082(1.037-4.088)$ \\
\hline
\end{tabular}

Table 4. Outcomes according to risk categorization in the validation phase

\begin{tabular}{|c|c|c|c|}
\hline & Low risk $(n=46)$ & Intermediate risk $(n=26)$ & High risk $(n=28)$ \\
\hline Incidence of NODAT & $4(8.7)$ & $9(34.62)$ & $13(46.43)$ \\
\hline OR for high vs. low risk & & $5.34,95 \%$ Cl 2.9-11.8 & \\
\hline OR for high vs. intermediate risk & & $1.34,95 \% \mathrm{Cl} 1.169-9.82$ & \\
\hline OR for intermediate vs. low risk & & $3.98,95 \% \mathrm{Cl} 2.1-6.7$ & \\
\hline
\end{tabular}

statistic for the multivariable model was $0.79(95 \% \mathrm{Cl}$ 0.74-0.89).

\section{Development of scoring system}

Therefore, according to the OR obtained, the scoring system was established as follows:

- age $\geq 38.5$ years $(\mathrm{OR}=1.231)$ : 1 point;

- $B M I \geq 23.5 \mathrm{~kg} / \mathrm{m}^{2}(\mathrm{OR}=2.103): 2$ points;

- HOMA-IR $\geq 2.5(\mathrm{OR}=4.062): 4$ points;

- FBS on $1^{\text {st }} P O D \geq 159.5(O R=1.011): 1$ point, and

- FBS $5^{\text {th }}$ day $P O D \geq 122.5$ (OR $\left.=2.082\right): 2$ points.

As the highest possible score was 10 points, we divided it in tertiles so that we could assign each patient to one of three categories according to the score sum value: low-risk when it was 0 to 2 , intermediate-risk when it was 3 to 6 and high-risk when it was 7 to 10.

\section{Validation phase}

One hundred patients entered this phase of the study. Baseline characteristics were similar to the first except for a slightly higher prevalence of family history of diabetes in the validation cohort. The incidence of NODAT was similar in the development phase $(24 \%)$ and validation phase (26\%).

The incidence of NODAT occurred in $8.7 \%$ of low risk patients, $34.62 \%$ of intermediate risk and $46.43 \%$ of high risk patients (OR for high vs. low risk: $5.34,95 \%$ Cl 2.9-11.8, $\mathrm{P}<0.001$; OR for high vs. intermediate risk: $1.34,95 \% \mathrm{Cl} 0.69-9.82, \mathrm{P}=0.044$; OR for intermediate vs. low risk: $3.98,95 \% \mathrm{Cl} 2.1-6.7, \mathrm{P}=0.001$ ).

Predictive power of the score, as assessed by the C statistic was 0.78 (95\% Cl 0.67-0.88), similar to that found for the multivariate model.

\section{Discussion}

Although many demographic, clinical and biochemical markers have been clearly shown to correlate with development of NODAT, few efforts have been made to group them in order to improve their individual predictive power.

The scoring system proposed here is quite simple to implement and has a good ability to discriminate risk according to the $\mathrm{C}$-statistic value. All the information needed in our study to predict NODAT namely age, BMI, HOMA-IR and FBS are easily available. All of these are non-expensive and most importantly, they have a very good prognostic value. We divided the population studied into three groups: low, intermediate and high risk, which is a common practice among clinicians regarding many chronic diseases.

In the present study, age $>38.5$ years was found to be a significant predictor for the development of NODAT. Increasing age is associated with increased risk for NODAT aspecially over the age of 40 years $[6,10,12]$. A study by Crosio et al. in 2078 patients showed that patients older than 45 years were 2.9 times increased risk of developing diabetes [13]. Every 10-year increase in age leads to 1.5-fold increased risk of diabetes [14].

In our study, pre-transplant BMI $>23.5 \mathrm{~kg} / \mathrm{m}^{2}$ is found to be significant prognostic variable for development of NODAT. Obesity independently correlates with the development of NODAT [3-5, 15, 16]. An analysis of 15,309 patients using the Organ Procurement and Transplant Network/United Network for Organ Sharing (OPTN/UNOS) database found that the risk of NODAT increased 1.4-fold for those with a BMI of 25-30 and nearly doubled if the BMI was > 30 [17]. It remains unclear whether weight gain after transplantation is 
the cause, however one study suggested pre-transplant weight increases the risk for NODAT [18].

Midtvedt et al. using hyperinsulinaemia euglycemic clamps found insulin resistance as a common denominator of KTRs with NODAT and IGT [19]. In study done by Bayes et al. NODAT patients showed significantly higher pre-transplant plasma insulin concentrations and HOMA-IR index compared to non-NODAT patients [20]. We found HOMA-IR of more than 2.5 had an OR of 4.062 for NODAT development.

Patients with post-transplant hyperglycemia in our study had a fourfold higher risk of developing NODAT. Similar results were seen in the study by Chakkera et al. in 200 posttransplant patients in Arizona [21]. A study from Chile reported 5.4-fold higher risk of developing diabetes in patients with early hyperglycemia [22]. A French study found first post-transplantation capillary blood glucose and fasting blood glucose on 1 st day tended to be higher in patients who developed diabetes 3 months later [23]. They reported maximum hyperglycaemia on the first post-operative day which decreased gradually during first 4 days of transplantation probably related to decrease in corticosteroid dosages and reduction in insulin resistance due to resolution of uraemia. A Belgian study demonstrated that a normal OGTT on the $5^{\text {th }}$ post-operative day was associated with a significantly decreased risk of NODAT at 3 months [24]. We also found that persistent postoperative day $5^{\text {th }}$ FBS to have a higher odd of NODAT development compared to day 1 FBS. The significant risk of NODAT posed by posttransplant hyperglycaemia makes it prudent to follow up these patients more diligently and are likely to benefit from intensive glucose monitoring. Based on the available evidence, NODAT cannot be efficiently prevented by tailored immunosuppression alone without compromising kidney graft survival. In the TIP-study, early use of basal insulin in the immediate post-transplantation period lower odds of NODAT by $73 \%$ throughout 1 year of follow-up [25].

Only one previous study in predominantly white transplant recipients described a pretransplant predictive risk model for NODAT using seven pretransplant variables (age $\geq 50$ years, planned use of maintenance corticosteroids; use of gout medicine; $\mathrm{BMI} \geq 30 \mathrm{~kg} / \mathrm{m}^{2}$; fasting glucose $\geq 100 \mathrm{mg} / \mathrm{dL}$; fasting triglycerides $\geq 200 \mathrm{mg} / \mathrm{dL}$; and family history of type 2 diabetes) [26]. But they did not consider peri-transplant risk factors like immediate post-operative hyperglycemia which are strongly associated with NODAT. Moreover, there is variability in the use of gout medication and corticosteroids. In our study, be had a standard immunosuppressive regimen for best transplant outcome in all patients and according to OR obtained, scoring system using five variables (age $\geq 38.5$ years; $\mathrm{BMI} \geq$ $23.5 \mathrm{~kg} / \mathrm{m}^{2}$; HOMA-IR $\geq 2.5$; FBS on $1^{\text {st }} \mathrm{POD} \geq 159.5$; FBS $5^{\text {th }}$ day $P O D \geq 122.5$ ) was established. There is always a concern of higher mortality in the person who develops NODAT which warrants adaptation of risk scores in routine clinical setting by transplant physicians. A study by Cooper et al. with 266 participants undergoing kidney transplantation found the age and sex adjusted mortality to be 1.69 times higher among patients with NODAT versus those without NODAT, hazard ratio $2.69(95 \% \mathrm{Cl} 1.04-7.01)$ [27]. Cosio et al. described two fold increase in mortality with NODAT compared to nontransplant recipients, which was equal to that of pretransplant diabetes and independent of other factors known to reduce survival [28].

\section{Conclusion}

The morbidity and mortality associated with NODAT makes it prudent to a identify risk factors and develop a risk score for early detection of NODAT and stratify effective strategies for prevention and intensive treatment in resource-limited setting wherein extensive monitoring in all patients is expensive. This new scoring framework is basic and simple to accomplish. It permits a generally excellent stratification of risk of developing NODAT in patients undergoing renal transplantation. They might be separated in three risk stratification cohorts, which could be of help in the decision-making process. Our findings should be tested in a larger cohort of patients in order to suggest clinical strategies based on them. If these data were confirmed, a highly aggressive approach as per recent evidences can be recommended in high risk and intermediate risk patients and a more conservative one could be reserved for the low risk group.

\section{Conflict of interest}

The authors declare to have no conflict of interest.

\section{REFERENCES}

1. Davidson J, Wilkinson A, Dantal J, et al. New-onset diabetes after transplantation: 2003 International consensus guidelines. Proceedings of an international expert panel meeting. Barcelona, Spain, 19 February 2003. Transplantation. 2003; 75: SS3.

2. Wilkinson A, Davidson J, Dotta F, et al. Guidelines for the treatment and management of new-onset diabetes after transplantation. Clin Transplant. 2005; 19(3): 291-298, doi: 10.1111/j.13990012.2005.00359.x, indexed in Pubmed: 15877787.

3. Kasiske BL, Snyder JJ, Gilbertson D, et al. Diabetes mellitus after kidney transplantation in the United States. Am J Transplant. 2003; 3(2): 178-185, doi: 10.1034/j.1600-6143.2003.00010.x, indexed in Pubmed: 12603213.

4. Boudreaux JP, McHugh L, Canafax DM, et al. The impact of cyclosporine and combination immunosuppression on the incidence of posttransplant diabetes in renal allograft recipients. Transplantation. 1987; 44(3): 376-381, doi: 10.1097/00007890-19870900000010, indexed in Pubmed: 3307061. 
5. Cosio FG, Pesavento $T E$, Kim S, et al. Patient survival after renal transplantation: IV. Impact of post-transplant diabetes. Kidney Int. 2002; 62(4): 1440-1446, doi: 10.1111/j.1523-1755.2002. kid582.x, indexed in Pubmed: 12234317.

6. Gunnarsson R, Arner P, Lundgren $G$, et al. Diabetes mellitus - a more-common-than-believed complication of renal transplantation. Transplant Proc. 1979; 11(2): 1280-1281, indexed in Pubmed: 382510.

7. Gaston RS, Basadonna G, Cosio FG, et al. National Kidney Foundation Task Force on Diabetes and Transplantation. Transplantation in the diabetic patient with advanced chronic kidney disease: a task force report. Am J Kidney Dis. 2004; 44(3): 529-542, indexed in Pubmed: 15332226.

8. Caillard S, Eprinchard L, Perrin P, et al. Incidence and risk factors of glucose metabolism disorders in kidney transplant recipients: role of systematic screening by oral glucose tolerance test. Transplantation. 2011; 91(7): 757-764, doi: 10.1097/ TP.0b013e31820f0877, indexed in Pubmed: 21336240.

9. Sulanc E, Lane JT, Puumala SE, et al. New-onset diabetes after kidney transplantation: an application of 2003 International Guidelines. Transplantation. 2005; 80(7): 945-952, doi: 10.1097/01. tp.0000176482.63122.03, indexed in Pubmed: 16249743.

10. Chakkera HA, Knowler WC, Devarapalli $Y$, et al. Relationship between inpatient hyperglycemia and insulin treatment after kidney transplantation and future new onset diabetes mellitus. Clin J Am Soc Nephrol. 2010; 5(9): 1669-1675, doi: 10.2215/ CJN.09481209, indexed in Pubmed: 20558559.

11. American Diabetes Association. Classification and diagnosis of diabetes. Sec. 2. In Standards of Medical Care in Diabetes 2017. Diabetes Care. 2017; 40(Suppl. 1): S11-S24.

12. Montori VM, Basu A, Erwin PJ, et al. Posttransplantation Diabetes: A systematic review of the literature. Diabetes Care. 2002; 25(3): 583-592, doi: 10.2337/diacare.25.3.583.

13. Cosio FG, Pesavento TE, Kim S, et al. Patient survival after renal transplantation: IV. Impact of post-transplant diabetes. Kidney Int. 2002; 62(4): 1440-1446, doi: 10.1111/j.1523-1755.2002. kid582.x, indexed in Pubmed: 12234317.

14. Gourishankar S, Jhangri GS, Tonelli M, et al. Development of diabetes mellitus following kidney transplantation: a Canadian experience. Am J Transplant. 2004; 4(11): 1876-1882, doi: 10.1111/j.16006143.2004.00591.x, indexed in Pubmed: 15476489.

15. Kasiske BL, Snyder JJ, Gilbertson D, et al. Diabetes mellitus after kidney transplantation in the United States. Am J Transplant. 2003; 3(2): 178-185, doi: 10.1034/j.1600-6143.2003.00010.x indexed in Pubmed: 12603213.

16. Boudreaux JP, McHugh L, Canafax DM, et al. The impact of cyclosporine and combination immunosuppression on the incidence of posttransplant diabetes in renal allograft recipients. Transplantation. 1987; 44(3): 376-381, doi: 10.1097/00007890-19870900000010, indexed in Pubmed: 3307061.

17. Shah T, Kasravi A, Huang $E$, et al. Risk factors for development of new-onset diabetes mellitus after kidney transplantation.
Transplantation. 2006; 82(12): 1673-1676, doi: 10.1097/01. tp.0000250756.66348.9a, indexed in Pubmed: 17198258.

18. Marrero D, Hernandez D, Tamajón LP, et al. For the Spanish Late Allograft Dysfunction Study Group. Pre-transplant weight but not weight gain is associated with new-onset diabetes after transplantation: a multi-centre cohort Spanish study. NDT Plus. 2010; 3(Suppl_2): ii15-ii20, doi: 10.1093/ndtplus/sfq065, indexed in Pubmed: 20508859.

19. Midtvedt K, Hartmann A, Hjelmesaeth J, et al. Insulin resistance is a common denominator of post-transplant diabetes mellitus and impaired glucose tolerance in renal transplant recipients. Nephrol Dial Transplant. 1998; 13(2): 427-431, doi: 10.1093/ oxfordjournals.ndt.a027841, indexed in Pubmed: 9509457.

20. Bayés $B$, Lauzurica $R$, Granada $M L$, et al. Adiponectin and risk of new-onset diabetes mellitus after kidney transplantation. Transplantation. 2004; 78: 26-30.

21. Chakkera HA, Knowler WC, Devarapalli Y, et al. Relationship between inpatient hyperglycemia and insulin treatment after kidney transplantation and future new onset diabetes mellitus. Clin J Am Soc Nephrol. 2010; 5(9): 1669-1675, doi: 10.2215/ CJN.09481209, indexed in Pubmed: 20558559.

22. Maldonado F, Tapia G, Ardiles L. Early hyperglycemia: a risk factor for posttransplant diabetes mellitus among renal transplant recipients. Transplant Proc. 2009; 41(6): 2664-2667, doi: 10.1016/j. transproceed.2009.06.133, indexed in Pubmed: 19715996.

23. Wojtusciszyn A, Mourad G, Bringer J, et al. Continuous glucose monitoring after kidney transplantation in non-diabetic patients: early hyperglycaemia is frequent and may herald post-transplantation diabetes mellitus and graft failure. Diabetes Metab. 2013; 39(5): 404-410, doi: 10.1016/j.diabet.2012.10.007, indexed in Pubmed: 23999231.

24. Boudreaux JP, McHugh L, Canafax DM, et al. The impact of cyclosporine and combination immunosuppression on the incidence of posttransplant diabetes in renal allograft recipients. Transplantation. 1987; 44(3): 376-381, doi: 10.1097/00007890-19870900000010, indexed in Pubmed: 3307061.

25. Hecking $M$, Haidinger $M$, Döller $D$, et al. Early basal insulin therapy decreases new-onset diabetes after renal transplantation. J Am Soc Nephrol. 2012; 23(4): 739-749, doi: 10.1681/ ASN.2011080835, indexed in Pubmed: 22343119.

26. Chakkera HA, Chang YH, Ayub A, et al. Validation of a pretransplant risk score for new-onset diabetes after kidney transplantation. Diabetes Care. 2013; 36(10): 2881-2886, doi: 10.2337/ dc13-0428, indexed in Pubmed: 24009296.

27. Cooper L, Oz N, Fishman G, et al. New onset diabetes after kidney transplantation is associated with increased mortality - A retrospective cohort study. Diabetes Metab Res Rev. 2017; 33(8), doi: 10.1002/dmrr.2920, indexed in Pubmed: 28731619.

28. Cosio FG, Pesavento TE, Kim S, et al. Patient survival after renal transplantation: IV. Impact of post-transplant diabetes. Kidney Int. 2002; 62(4): 1440-1446, doi: 10.1111/j.1523-1755.2002. kid582.x, indexed in Pubmed: 12234317. 